\title{
Does CCS reduce power generation flexibility? A dynamic study of combined cycles with post-combustion $\mathrm{CO}_{2}$ capture
}

\author{
Jairo Rúa ${ }^{\mathrm{a}}$, Mai Bui ${ }^{\mathrm{b}, \mathrm{c}}$, Lars O. Nord ${ }^{\mathrm{a}}$, Niall Mac Dowell ${ }^{\mathrm{b}, \mathrm{c}, *}$ \\ ${ }^{a}$ Department of Energy and Process Engineering, Norwegian University of Science and Technology, Trondheim, \\ Norway \\ ${ }^{b}$ Centre for Process Systems Engineering, Imperial College London, London, UK \\ ${ }^{c}$ Centre for Environmental Policy, Imperial College London, London, UK
}

\begin{abstract}
To date, the deployment, integration, and utilisation of intermittent renewable energy sources, such as wind and solar power, in the global energy system has been the cornerstone of efforts to combat climate change. At the same time, it is recognised that renewable power represents only one element of the portfolio of technologies that will be required to deliver a technically feasible and financially viable energy system. In this context, carbon capture and storage (CCS) is understood to play a uniquely important role, providing significant value through flexible operation. It is therefore of vital importance that CCS technology can operate synergistically with intermittent renewable power sources, and consequently ensuring that CCS does not inhibit the flexible and dispatchable nature of thermal power plants. This work analyses the intrinsic dynamic performance of the power and $\mathrm{CO}_{2}$ capture plants independently and as an integrated system. Since the power plant represents the fast dynamics of the system and the steam extraction is the main point of integration between the $\mathrm{CO}_{2}$ capture and power plants, disturbances with fast dynamics are imposed on the steam extraction valve during steady state and dynamic operation of a natural gas combined cycle (NGCC) to study the effects of the integration on power generation capacity. The results demonstrate that the integration of liquid-absorbent based post-combustion $\mathrm{CO}_{2}$ capture has negligible impact on the power generation dynamics of the NGCC.
\end{abstract}

Keywords: combined cycle gas turbine (CCGT), post-combustion $\mathrm{CO}_{2}$ capture, amine absorption process, monoethanolamine (MEA), flexible operation, dynamic operation, dynamic modelling

\footnotetext{
*Corresponding author.

Email addresses: jairo.r.pazos@ntnu.no (Jairo Rúa), m.bui@imperial.ac.uk (Mai Bui), lars.nord@ntnu.no (Lars O. Nord), niall@imperial.ac.uk (Niall Mac Dowell)
}

Among the different possibilities available to reduce the greenhouse gas emissions, carbon capture and storage (CCS) is a uniquely important technology for mitigating the $\mathrm{CO}_{2}$ emissions associated with the energy sector and industry (IPCC, 2005, 2014). These two sectors account for more than $50 \%$ of the total global greenhouse gas emissions (IPCC, 2014; IEA, 2018a).

Renewable energy sources will also contribute significantly to reducing $\mathrm{CO}_{2}$ emissions (IEA, 2018b). Future energy systems are expected to be characterised by a high penetration of intermittent renewable sources. This will result in additional costs associated with load balancing, additional firming capacity, 
energy storage, and interconnection capacity 79 (Heuberger et al., 2017a,b).

Flexible dispatchable energy generation 81 technologies such as thermal power with CCS 82 offer a cost effective way to balance this inter- 83 mittency (Heuberger et al., 2016; Kondziella 84 and Bruckner, 2016; Montañés et al., 2016; 85 Mac Dowell and Staffell, 2016). Consequently, 86 thermal power plants will be exposed to cy- 87 cling operation and more frequent start-ups 88 and shut-downs (Eser et al., 2017; González- 89 Salazar et al., 2017). Thus, to deploy CCS 90 technology in a power market dominated by 91 the high variability of renewable energy, it is 92 necessary to prove its adequacy for flexible op- 93 eration (Adams and Mac Dowell, 2016). 94

Post-combustion $\mathrm{CO}_{2}$ capture is arguably ${ }^{95}$ the most mature CCS technology (IPCC, 2005; Bui et al., 2018a). Therefore, deep under- ${ }^{97}$ standing of the dynamic performance of these ${ }^{98}$ capture plants integrated with thermal power ${ }^{9}$ plants is essential. Dynamic modelling and ${ }^{100}$ simulation remains the primary medium to ${ }^{101}$ study the interaction of these systems under ${ }^{102}$ transient operation due to the lack of full- 103 scale experience (Bui et al., 2014, 2018a). De- 104 veloping further detailed insight into the pro- 105 cess dynamics could help improve the accu- 106 racy and robustness of dynamic process control 107 and scheduling during flexible operation, plant 108 start-up and shut-down.

The development of dynamic $\mathrm{CO}_{2}$ capture ${ }^{110}$ models was extensively reviewed by Bui et al. ${ }^{111}$ (2014, 2018b). Whilst the vast majority of re- 112 search on flexible operation of CCS focuses on ${ }^{113}$ modelling the dynamics of the capture plant, 114 there are relatively few studies that model 115 the integrated system with a thermal power 116 plant (Lawal et al., 2012; Mac Dowell and 117 Shah, 2013, 2015; Wellner et al., 2016; He ${ }^{118}$ and Ricardez-Sandoval, 2016; Mechleri et al., ${ }^{119}$ 2017a,b; Garðarsdóttir et al., 2017; Montañés 120 et al., 2017b).

Lawal et al. (2012) studied the dynamic in- ${ }^{122}$ teraction between a coal-fired power plant and ${ }^{123}$ a post-combustion capture plant with MEA, ${ }^{124}$ and showed how tight control (i.e., rapidly re- ${ }^{125}$ sponds to minimise deviation between the con- 126 trolled variable and its set-point) on the cap- 127 ture plant may interfere with the power output 128 of the power plant. For a similar integrated 129 system, Garðarsdóttir et al. (2017) found that power generation settling times are essentially independent of the integration of the capture plant. However, inadequate control strategies may result in unnecessary longer stabilization times. Both studies concluded that the dynamics of the capture plant are significantly slower than the power plant, leading to longer settling times in the absence of adequate control structures, which may affect power plant performance. Retrofitted coal power plants exhibit the same transient behaviour and the integration with the capture plant acts as steam storage that can be rapidly adjusted to meet peak power demands through the manipulation of the extraction valve (Wellner et al., 2016). Mac Dowell and Shah (2013, 2015), and Mechleri et al. (2017a,b) also developed integrated systems of coal-fired power plants with postcombustion capture plants to study the economic performance during flexible operation accounting for variations in the electricity market, although the dynamic interaction was not studied.

Commercial natural gas combined cycles integrated with full-scale post-combustion capture plants show similar transient performance. He and Ricardez-Sandoval (2016) and Montañés et al. (2017b) proved the faster dynamics of the power plant compared to the capture plant, which resulted in slow oscillations in the longer time-scales as a consequence of the interaction between both plants. The analysis of varying inputs in open-loop in the capture plant also showed the benefits that may be obtained from close-loop control and simultaneous scheduling of the power and $\mathrm{CO}_{2}$ capture plant (He and Ricardez-Sandoval, 2016). Further, evaluation of several control structures in the capture plant showed that different control couplings may lead to distinct long term dynamics in the low-pressure steam turbine. Nevertheless, the short-term transient behaviour of the natural gas combined cycle is not affected as a result of the slow dynamic response of the post-combustion capture plant (Montañés et al., 2017b).

These studies on the full-scale transient performance of integrated systems showed that slow dynamic interactions between the thermal power plant with the post-combustion $\mathrm{CO}_{2}$ 
capture plant do not affect notably their power 179 production capacity, albeit the stabilization 180 time is affected by the slow response of the cap- 181 ture plant. However, the dynamics of power 182 generation are determined by the transient be- 183 haviour of the steam cycle, that is, by the fast 184 dynamics of the integrated system. The de- 185 coupling of power generation capacity from the 186 CCS process has the potential to significantly 187 enhance the economic efficiency and the tech- 188 nical performance. Therefore, rapid dynamic 189 disturbances must be analysed in order to de- 190 termine whether the $\mathrm{CO}_{2}$ capture plant lim- ${ }_{191}$ its the electricity production capabilities of the ${ }_{192}$ thermal power plant.

The aim of this study is to investigate the ${ }_{194}$ extent to which fast disturbances in the steam ${ }_{195}$ extraction affect the power generation capabil- ${ }_{196}$ ity of the integrated system. Building on previ- ${ }_{197}$ ous work, a thorough analysis of the dynamics ${ }_{198}$ governing the thermal power plant, the post- ${ }_{199}$ combustion capture plant and the integrated ${ }_{200}$ system is included in Section 2 to understand 201 the physical mechanisms dictating their tran- ${ }_{202}$ sient operation. Section 3 describes the mod- 203 elling of the natural gas combined cycle inte- 204 grated with the post-combustion $\mathrm{CO}_{2}$ capture ${ }_{205}$ plant and the special power generation characteristic of this type of power generation systems. Results are presented and discussed in ${ }^{207}$ Section 4, and the conclusions are presented in ${ }_{209}^{208}$ Section 5 .

\section{Dynamic Analysis of Thermal Power Plants Integrated with CCS}

Thermal power plants and post-combustion ${ }^{214}$ capture plants exhibit distinct dynamic be- ${ }^{215}$ haviour. This section identifies and evaluates ${ }^{216}$ the process and dominant dynamics that sig- ${ }^{217}$ nificantly influence thermal power plants in- ${ }^{218}$ tegrated with post-combustion $\mathrm{CO}_{2}$ capture ${ }^{219}$ plants, including passive elements that con- ${ }^{220}$ tribute to the dynamics but are not the main ${ }^{221}$ source.

\subsection{Thermal Power Plants}

As post-combustion capture plants are a cost 225 effective technology to remove $\mathrm{CO}_{2}$ from large- 226 emission sources, they are a suitable comple- 227 ment for heavy-duty natural gas combined cy- 228 cles and coal- and biomass-fired power plants 229
(IPCC, 2005). Natural gas combined cycles rely on gas turbines to control and produce most of the power and a steam cycle that acts as a passive element, which utilizes the energy contained in the exhaust gas to generate extra power. In contrast, power generation from solid fuels, namely coal and biomass, using subcritical and supercritical power plant technology, produce electricity solely via the steam cycle, which is driven by the combustion process in the furnace.

Fig. 1 shows the different operation range of each thermal power plant. The minimum load of modern gas turbine is limited to $40 \%$ of its full load owing to the combustion stability of the fuel and the associated emissions (Alobaid et al., 2017; Eser et al., 2017). Therefore, since the gas turbine accounts for a large share of the total power capacity of natural gas combined cycles, this type of power plants cannot reduce its power generation below this limit. Conversely, coal and biomass power plants are not restricted by a gas turbine; and their minimum compliant load is around $25 \%$ of their full load (Hentschel et al., 2016). This broader operation range enhances the utilisation of coal and biomass power plants as spinning reserves.

A common characteristic of all thermal power plants is the heat transfer in the steam generator between the combustion gases and the working fluid of the Rankine cycle. In this equipment, the combustion gases flow in a counter-current or cross-flow manner through several tube bundles where energy is transferred progressively to produce the superheated steam that drives the steam turbines. Steam generators are bulky equipment whose enormous mass of metal stores large amounts of energy due to its heat capacity. This leads to slow responses in the steam cycle and hence the power generation in the steam turbines. Thus, steam generators are the main limitation during the transient operation of thermal power plants and consequently define their dominant dynamics (Alobaid et al., 2017).

Two different time-scales dictate the dynamic operation of natural gas combined cycles. Modern gas turbines are fast components that can have load ramps up to $15 \%$ per minute and whose dominant dynamics are in the order of seconds (Hentschel et al., 2016). Steam 


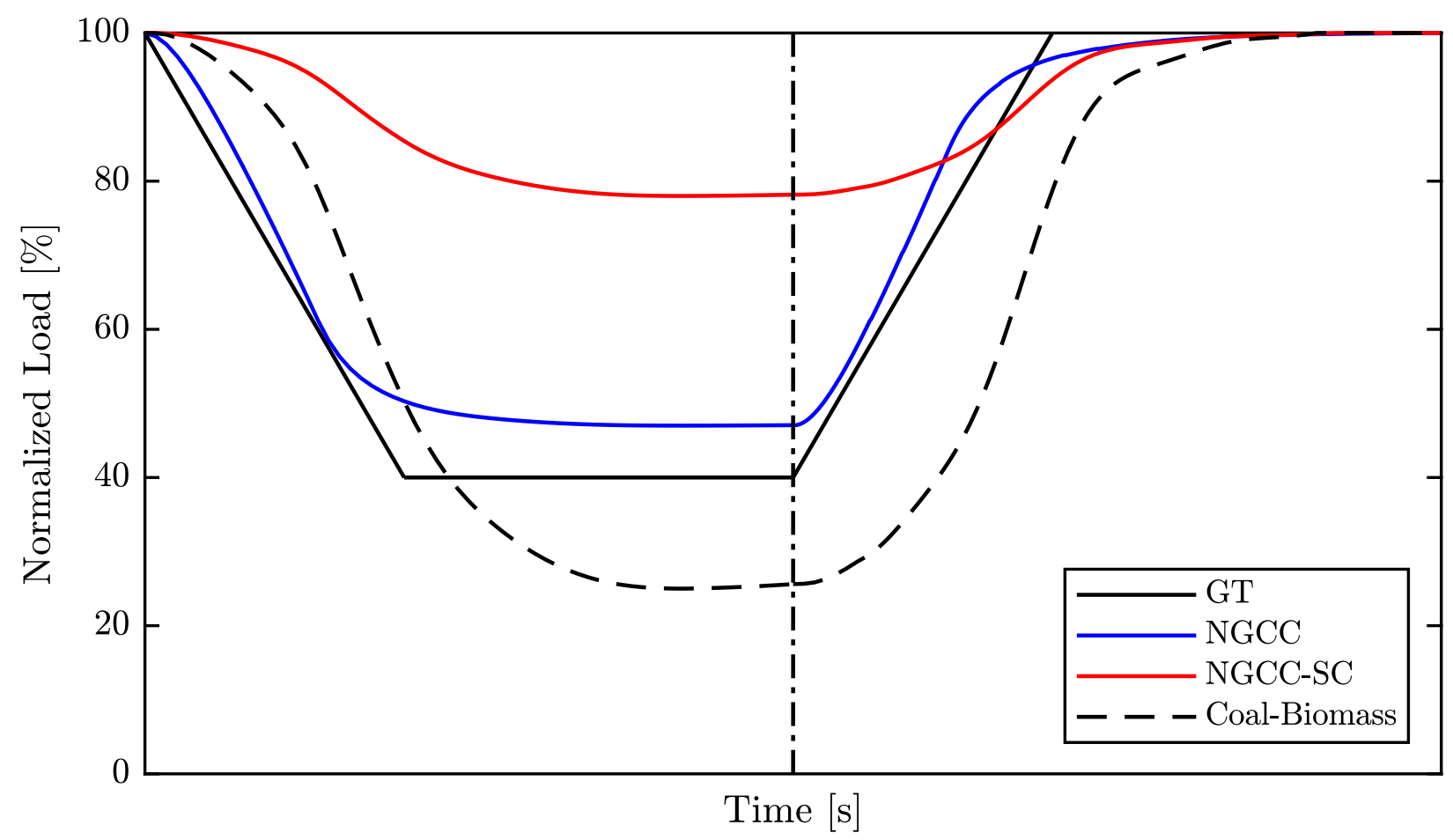

Figure 1: Generic dynamic behaviour of different thermal power plants of similar size. Maximum and minimum loads and power generation shares depend on the power plant design. The vertical line indicates the increasing load dynamic behaviour. The nomenclature is as follows. GT: Gas Turbine, NGCC: Natural Gas Combined Cycle, SC: Steam Cycle.

cycles are limited by the heat capacitance of 256 the steam generator and thus their dominant 257 dynamics are on the order of minutes. Fig. 1258 represents the general dynamic behaviour of a 259 natural gas combined cycle. The gas turbine 260 drives the transient operation of the NGCC by 261 changing its load, whilst the steam cycle deter- 262 mines the time required to reach steady-state (Kehlhofer et al., 2009). Nevertheless, natural 263 gas combined cycles are able to meet the power demand before the steam cycle reaches steady- ${ }^{264}$ state by under- or over-shooting the gas turbine ${ }^{265}$ (Rúa et al., 2020). This unique ability of the ${ }^{266}$ gas turbine compensates for the slow transient ${ }^{267}$ performance of the steam cycle, enhancing the ${ }_{269}^{268}$ adequacy of NGCC for flexible operation.

Coal and biomass power plants do not have 271 a gas turbine to control the power generation, 272 thus governor valves are required at the inlet 273 of the steam turbine to guarantee tight power 274 control during transient operation. Fuel con- 275 sumption is adjusted according to power de- 276 mand to regulate the part-load performance, 277 but this strategy cannot be applied in the time- 278 scale of seconds owing to the heat capacitance 279 of the steam generator and the slow response 280 of the steam cycle (see Fig. 1). Consequently, the slow dynamics of the steam cycle dominate the transient operation of coal and biomass power plants, making them slower than modern NGCC and less suitable for flexible operation (Eser et al., 2017; González-Salazar et al., 2017).

\subsection{Post-Combustion Capture Plants}

Capture plants are passive systems whose operation is determined by the conditions of the gas to be treated and the steam available for the reboiler. From a dynamic operation perspective, the gas is a disturbance to which the capture plant must adapt to, whereas the steam is considered a manipulated variable. The stripper condenser pressure is also a boundary condition of the capture plant, however, this is considered constant as it is rarely modified during dynamic operation.

In a post-combustion capture plant, the fastest units are the rotating machinery (i.e., blowers, compressors and pumps), as they have almost negligible dynamics with time constants in the order of a few seconds. Thus, solvent flow rates stabilize within a few minutes, de- 
pending on the size of the plant and the mag- 332 nitude of the flow change (Flø et al., 2016; 333 Montañés et al., 2018). Heat exchangers and 334 piping lead to transport delays that do not af- 335 fect the nature of the dynamics. Conversely, 336 large vessels such as absorber and stripper 337 sumps, reboiler hotwells or buffer tanks in- 338 troduce significant inertia, which buffers and 339 smooths the overall dynamic behaviour of the 340 capture plant (Flø et al., 2016). Liquid hold-up 341 in the absorber and stripper also contributes to 342 this buffering effect, however, the effect on the 343 solvent flow rate dynamics is small relative to 344 that of sumps, storage tanks, etc. Therefore, 345 the dynamics of the post-combustion capture 346 plant are not governed by the mass balance 347 but by the total volume of solvent, the volu- 348 metric capacity of the plant, and the solvent 349 circulation time.

Chemical and thermal equilibrium in the ab- ${ }^{351}$ sorber and stripper columns also affect the ${ }^{352}$ transient behaviour but has a minor influence ${ }^{353}$ on the stabilisation time of the capture plant. ${ }^{354}$ (Flø et al., 2016; Tait et al., 2016; Montañés 355 et al., 2017a, 2018). During open-loop oper- ${ }^{356}$ ation, changes in flue gas flow rate primarily ${ }^{357}$ impacts the absorption section, affecting the ${ }^{358}$ $\mathrm{CO}_{2}$ capture rate and shifting the temperature ${ }^{359}$ profile as a result of the difference in released ${ }^{360}$ energy from the exothermic chemical reactions ${ }^{361}$ (Kvamsdal and Rochelle, 2008; Bui et al., 2016; ${ }^{362}$ Tait et al., 2016; Montañés et al., 2018). Both ${ }^{363}$ changes are dominated by the chemical and ${ }^{364}$ thermal inertia within the absorber as the sta- ${ }^{365}$ bilization times of the absorber temperature ${ }^{366}$ profile and $\mathrm{CO}_{2}$ capture rate are larger than ${ }^{367}$ the rise time of the flue gas flow rate (Montañés ${ }^{368}$ et al., 2018).

For a given solvent flow rate, moderate ${ }^{370}$ changes to the exhaust gas flow rate have a mi- ${ }^{372}$ nor effect on the rich $\mathrm{CO}_{2}$ loading of the solvent ${ }_{373}$ (Lawal et al., 2010; Flø et al., 2016; Bui et al., 2016; Montañés et al., 2017a, 2018; Bui et al., 2018b). However, sufficiently large variations in the feed gas $\mathrm{CO}_{2}$ concentration or mass flow ${ }^{37}$ rate may lead to more pronounced effects on 376 rich solvent loading. Changes in flue gas flow 377 rate only affect the absorption section and the 378 solvent loading, but the effect of these changes 379 on the overall stabilization time of the entire 380 capture plant is essentially negligible.
The steam flow rate to the reboiler is an important process parameter. Sufficiently large changes to the steam flow rate will vary the temperature in the reboiler, and consequently the operating conditions of the stripper column. Assuming the other process conditions remain constant or are not adequately adapted, this would result in changes to the lean $\mathrm{CO}_{2}$ loading exiting the stripper. (Lawal et al., 2010; Garðarsdóttir et al., 2015; Flø et al., 2016; Montañés et al., 2017a; Bui et al., 2020). This change in lean loading affects the amount of $\mathrm{CO}_{2}$ the solvent can absorb, which in turn influences the energy released during the absorption reaction, the absorber column temperature profile and the $\mathrm{CO}_{2}$ capture rate. These operation changes are expected to result in different rich loadings, which will affect the stripper transient conditions (Lawal et al., 2010; Flø et al., 2016; Bui et al., 2016; Montañés et al., 2017a, 2018).

Slow and long dynamics can limit the rate of transient behaviour and increase solvent circulation time. There is a combination of factors that contribute to slow dynamics, these include (i) total volume of solvent stored or heldup in the capture plant, (ii) size of the vessels in the system which impacts residence time, and (iii) transport delay introduced by the heat exchangers and piping. There is also an observable inter-column interaction between the stripper and absorber conditions. In a plant with slow dynamics (e.g., owing to larger total liquid hold-up), changes to the solvent flow rate lead to slow variation of the rich and lean solvent loading. Thus, the slow interaction between the absorber and stripper columns due to the large liquid volumes (e.g., long solvent circulation time or slow transient behaviour) is the main bottleneck, slowing the response time during flexible operation of post-combustion capture plants.

\subsection{Thermal Power Plants Integrated with Post-Combustion Capture Plants}

Several process configurations to integrate the power and capture plants have been studied (Botero et al., 2009; Lucquiaud et al., 2009; Jordal et al., 2012; Jonshagen et al., 2012; Mac Dowell and Shah, 2014), with steam extraction from the crossover between 
the intermediate- and low-pressure (IP-LP) 433 steam turbines being the preferred option 434 (Lawal et al., 2012; Montañés et al., 2017b; 435 Garðarsdóttir et al., 2017). In this integra- 436 tion approach the steam extracted from the 437 steam turbine may be mixed with low-pressure 438 superheated steam in NGCC, and tempera- 439 ture is controlled by evaporative spray cooling 440 with pressurized water from the intermediate- 441 pressure economizer (Montañés et al., 2017b). ${ }_{442}$ In contrast, temperature control in coal or 443 biomass power plants is achieved by using feed- ${ }_{444}$ water downstream the condenser (Fernandez 445 et al., 2016; Garðarsdóttir et al., 2017).

Steam availability at the IP-LP crossover 447 does not limit the dynamic operation of inte- 448 grated system. This is largely due to the steam ${ }^{449}$ requirements of the $\mathrm{CO}_{2}$ capture plant being ${ }^{450}$ small compared the large amount of steam pro- 451 duced in the Rankine cycle of the thermal ${ }^{452}$ power plant (Jordal et al., 2012; Rezazadeh ${ }^{453}$ et al., 2015). As a result, steam can always ${ }^{454}$ be extracted by modifying the opening of the ${ }^{455}$ steam extraction valve. This equipment can ${ }^{456}$ move from fully open to fully closed in seconds 457 and thus their dynamics are negligible com- 458 pared to those governing the thermal power 459 plant and post-combustion capture plant.

System integration also includes the cooling ${ }^{461}$ and compression of the exhaust gas leaving the ${ }^{462}$ heat-recovery steam generation. From the per- ${ }^{463}$ spective of dynamic operability, treatment of ${ }^{464}$ this flue gas is not a major concern due to ${ }^{465}$ the fast the dynamics of the blowers utilized to ${ }^{466}$ overcome the absorber column pressure drop, ${ }^{467}$ and hence do not limit the capture plant pro- ${ }^{468}$ cess dynamics. The direct contact cooler only ${ }^{469}$ introduces time delays. Ideally, the equipment ${ }^{470}$ integrating the thermal power plant with the post-combustion capture plant should not slow ${ }_{471}$ the overall transient operation of the integrated system. However, this coupling may lead to in- ${ }_{472}$ teractions between both plants that can affect ${ }_{473}$ their dynamics.

As different time-scales govern the dynamic 475 operation of thermal power plants and post- 476 combustion capture plants, system integration 477 must consider the distinctively different pro- 478 cess dynamics. Whilst heat capacitance in the 479 steam generator limits the transient behaviour 480 of thermal power plants to an order of minutes, 481 typically 10-20 minutes for power plants of several hundred MW, the large solvent volumes and long circulation time in the $\mathrm{CO}_{2}$ capture plant might lead to stabilization times in the order of hours (Lawal et al., 2012; Montañés et al., 2017b; Garðarsdóttir et al., 2017).

The power demand defines the operation of the power plant and hence the mass flow rate of the exhaust gas. Whereas changes in the flue gas conditions do not affect the performance of the thermal power plant, such changes are a disturbance for the capture plant, which must adapt its operation to meet the $\mathrm{CO}_{2}$ capture targets. This may lead to different steam extraction rates that also modify the operating conditions in the power plant. If steam extraction variation occurs at a slow dynamics scale, i.e., the time-scale defined by the capture plant, small fluctuations and longer stabilization times are obtained in the power generation of the low-pressure steam turbine (Lawal et al., 2012; Garðarsdóttir et al., 2017; Montañés et al., 2017b). However, this type of interaction between both plants is not critical as the thermal power plants are faster than the slow-dynamic time-scales of the $\mathrm{CO}_{2}$ capture plant. Furthermore, steam extraction does not significantly influence the load of the power plant. On the contrary, steam extraction in the fast dynamic time-scale occurs simultaneously with the change of power plant load and may lead to dynamic interactions that compromise the power generation capacity of the system. Therefore, it is important to address this possible issue by studying the dynamic interaction between the thermal power plant and the CCS system in the fast dynamics time-scale, which are addressed in Sections 3 and 4.

\section{Dynamic Modelling}

In this study, a physics-based model of a 615 MW NGCC integrated with a 30 wt\% MEA-based post-combustion capture process was used to study the dynamic interaction of NGCC integrated with absorption $\mathrm{CO}_{2}$ capture Montañés et al. (2017b). Triple pressure steam cycles with reheat are the most efficient and common configuration of modern natural gas combined cycles (Alobaid et al., 2017; Kehlhofer et al., 2009). GT PRO (Ther- 
moflow, 2014) was utilized to design the natu- 533 ral gas combined cycle as it provides detailed 534 information about the geometry of the plant. 535 Full-physics dynamic modelling was carried out 536 in the Modelica-based (Modelica Association, 537 2019) software Dymola (Dassault Systemes, 538 2016) using the specialized Thermal Power li- 539 brary (Modelon, 2015).

Full-scale post-combustion capture plants ${ }^{541}$ are designed based on the flue gas $\mathrm{CO}_{2}$ con- ${ }^{542}$ centration and conditions (i.e., flow rate, tem- ${ }^{543}$ perature, pressure), the required $\mathrm{CO}_{2}$ capture ${ }^{544}$ rate, the maximum pressure drops in the ab- 545 sorber and stripper columns, column flooding limits and a reasonable balance between capital and operational costs (Jordal et al., 2012; Dutta et al., 2017). For the natural gas combined cycle considered in this work, a capture plant with two absorber columns in parallel ${ }^{548}$ and one stripper for a nominal $90 \% \mathrm{CO}_{2}$ capture rate was found to meet these requirements ${ }_{551}$ (Montañés et al., 2017b). A dual absorber pro- ${ }_{552}$ cess topology was selected due to the limits in ${ }_{553}$ column sizing and construction (Dutta et al., ${ }_{554}^{553}$ 2017).

Integration of the power and capture plants ${ }_{556}$ was achieved by extracting steam from the ${ }_{557}$ crossover between the intermediate- and low- 558 pressure steam turbines (see Section 2.3). ${ }_{559}$ Thus, the low-pressure section of the steam 560 turbine was designed for nominal conditions 561 where steam is extracted to achieve a $90 \%{ }_{562}$ capture rate. Fig. 2 represents the layout of ${ }_{563}$ the natural gas combined cycle integrated with ${ }_{564}$ the post-combustion capture plant. Details ${ }_{565}$ on the design data, performance indicators, ${ }_{566}$ modelling assumptions and validation results ${ }_{567}$ are presented in the work by Montañés et al. ${ }_{568}$ (2017b).

The design of the power plant steam cycle 570 includes the extraction of steam for the $\mathrm{CO}_{2} 571$ capture plant. Consequently, the power gen- 572 eration distribution between the different tur- 573 bines in this power plant differs from mod- 574 ern NGCC without a capture plant. Fig. 3575 represents the power generation distribution 576 at different gas turbine loads. The gas tur- 577 bine produces the majority of the power as 578 in any combined cycle without steam extrac- 579 tion, however, the contribution to the over- 580 all power generation of the low-pressure sec- 581 tion of the steam turbine is halved due to the steam extraction (Jordal et al., 2012; Rezazadeh et al., 2015). Therefore, the contribution of the low pressure section in electricity production and in the steam cycle diminishes as a result of the integration with the post-combustion capture system. The highand intermediate-pressure steam turbines contribute similarly as in NGCCs without steam extraction. This leads to larger power generation from the intermediate-pressure section because of the similar inlet temperature owing to the reheating and its larger pressure ratio.

\section{Results and Discussion: Dynamics of a NGCC with $\mathrm{CO}_{2}$ Capture}

The dynamics of the natural gas combined cycle occur in shorter time scales compared to the overall transient operation of the integrated system. Thus, to study whether the steam extraction coupling affects the power generation capacity in different dynamic operation scenarios, the variations in the opening of the extraction valve must be faster than the dominant dynamics of the thermal power part (see Section 2). A damping sine signal was hence superimposed on the extraction valve opening to ensure fast dynamics in the interface between the NGCC and the capture plant (Ljung, 1987). This signal was characterized by an offset of 0.69 and an amplitude of 0.29 , with a natural and damping frequencies of 0.01 and 0.001 $\mathrm{Hz}$, respectively. These values ensure that variations in the steam extraction occur faster than the dominant dynamics of the NGCC. Albeit highly oscillating valve movements do not occur in practice during open loop operation (i.e., no feedback control), these values generate a signal that provides sufficient variation in steam extraction from the IP-LP crossover valve. This will give insight into the transient effects of variations in steam extraction on power generation.

Two different scenarios were considered to analyse the integration effect on the power generation during both steady-state and transient operation of the power plant. In the case where the NGCC is at steady-state, the damping sine in the valve opening drives the dynamics of the system. In contrast, when there is a 
load change in the power plant, the dynam- 600 ics are dictated by simultaneous changes oc- 601 curring at the gas turbine and the steam extraction. Varying gas turbine loads directly af- 602 fect power production. Secondly, steam cycle 603 performance is influenced by change in exhaust 604 gas conditions (e.g., temperature and mass flow 605 rate), and variations in steam extraction. $\quad 606$

As optimal operation of the integrated sys- 607 tem is not the main objective of this work, 608 the NGCC only had a regulatory control layer, 609 which regulates the steam temperature at the 610 steam turbine inlet, levels in drums and con- ${ }_{611}$ denser, and the pressures in the deaerator and 612 the low-pressure drum. In the post-combustion capture plant, the levels in the large vessels 613 were exclusively controlled, fixing the solvent 614 flow rate to nominal conditions. Details of the 615 implementation of this control structure are included in the work by Montañés et al. (2017b).

\subsection{Effect of Steam Extraction During Steady State Operation of the NGCC}

In this study, a sinusoidal signal was imposed in the steam extraction valve during steady state operation of the NGCC to observe the effect of disturbances in the interface of the integrated system. The power generation distribution was analysed in the NGCC, whilst key performance indicators of the capture plant such the carbon capture ratio and the reboiler temperature were investigated.

\subsubsection{Power Generation Performance}

Several part-loads during steady state operation are considered in order to cover a wide op-

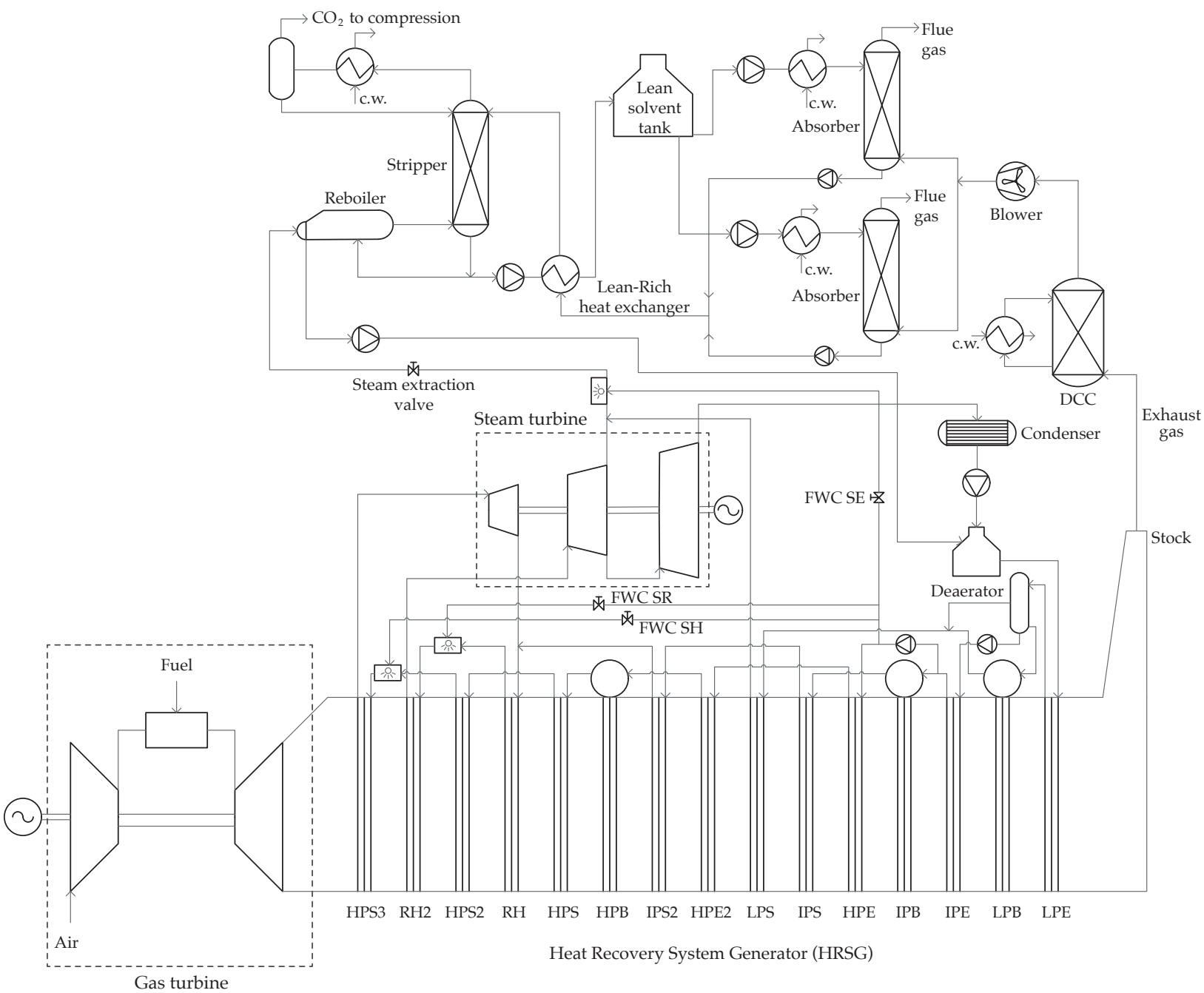

Figure 2: Process diagram of the natural gas combined cycle integrated with the post-combustion capture plant. The nomenclature is as follows. E: Economizer, B: Boiler, S: Superheater, R: Reheater P: Presure, L: Low, I: Intermediate, H: High, FWC: Feed-water cooling, RS: Reheated steam, SS: Superheated steam, SE: steam extraction, DCC: Direct contact cooler. 


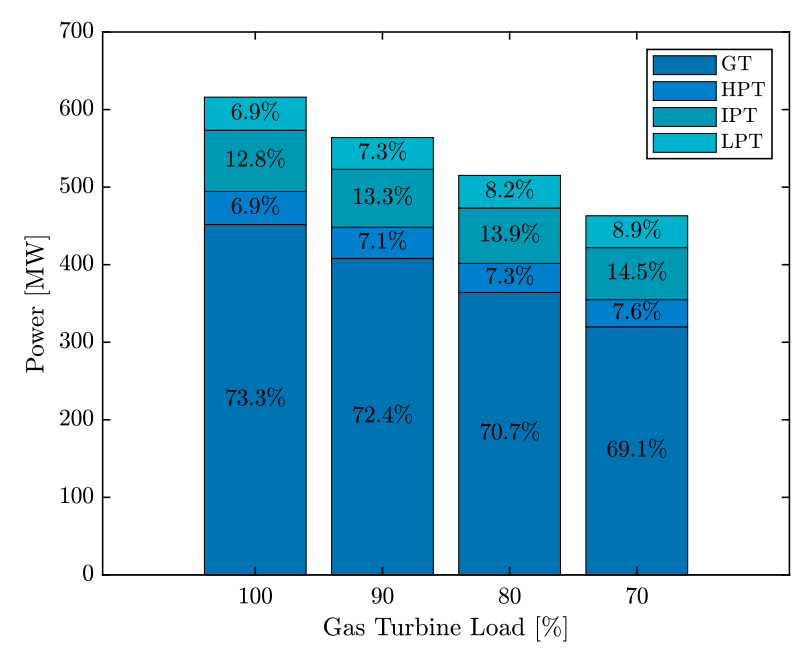

Figure 3: Power distribution of the natural gas combined cycle with CCS at different gas turbine loads. erational range of the NGCC integrated with ${ }^{666}$ post-combustion $\mathrm{CO}_{2}$ capture. Fig. 4 repre- ${ }^{667}$ sents the variation in mechanical power pro- ${ }^{668}$ duction in the NGCC and the different steam ${ }^{669}$ turbine sections due to variation in steam ex- ${ }^{670}$ traction from the IP-LP crossover. The open- ${ }^{671}$ ing of the steam extraction valve defines the ${ }^{672}$ mass flow rate of working fluid available for ${ }^{673}$ expansion, which appears to have the greatest ${ }^{674}$ impact on the low pressure section in Fig. 4d. ${ }^{675}$ The valve opening also alters the intermediate ${ }^{676}$ and low pressure sections of the steam cycle, ${ }^{677}$ leading to deviations in power generation by ${ }^{678}$ the intermediate-pressure section of the steam ${ }^{679}$ turbine, albeit to a lesser extent compared to ${ }^{680}$ the low-pressure counterpart.

The variation in power generation by the intermediate- and low-pressure steam turbines has a negligible impact on the total power produced by the NGCC. The reasons for this ef- ${ }^{686}$ fect is the gas turbine generates most of the ${ }^{687}$ total power and the average contribution from ${ }^{688}$ the IP and LP steam turbine sections is $20 \%{ }^{689}$ (see Fig. 3). Therefore, the variations induced ${ }^{690}$ by the steam extraction valve in the NGCC ${ }^{691}$ power generation during steady-state operation are negligible and can be easily compensated by the power controllers included in the gas turbine. Fig. 4a demonstrates how the variation ${ }^{694}$ in steam extraction only creates a small distur- 695 bances in the total power generation.

\subsection{2. $\mathrm{CO}_{2}$ Capture Performance}

Steam extraction dictates the steam flow rate to the reboiler of the post-combustion capture plant, thereby influencing the $\mathrm{CO}_{2}$ capture performance. Fig. 5 illustrates the effect of steam flow rate on reboiler temperature, lean loading and $\mathrm{CO}_{2}$ capture rate. The steam flow rate has an insignificant effect on the transient behaviour of the reboiler temperature, where variation is less than $0.2{ }^{\circ} \mathrm{C}$ (shown in Fig. $5 \mathrm{~d}$ ). Therefore, the operating conditions within the stripper column are relatively unaffected and the solvent lean loading (Fig. 5b) only deviates slightly from its steady-state value. This results in almost constant $\mathrm{CO}_{2}$ capture ratios, defined as the ratio of $\mathrm{CO}_{2}$ product over $\mathrm{CO}_{2}$ in the feed flue gas (see Fig. 5a).

Fig. 5 shows how the effect of large fluctuations in steam mass flow rate (Fig. 5c) is dampened in the $\mathrm{CO}_{2}$ capture system (described in Section 2.2). The dampening effect observed in these results are in line with previous dynamic operation studies discussed in Section 2.2. As steam flow rate fluctuates, the transfer of heat is limited by the heat capacitance of the equipment and fluid. Consequently, the change in reboiler temperature is dampened (Fig. 5d), that is, very little fluctuation observed. Hence, there is minor variation in the degree of solvent regeneration, which leads to limited change in lean loading (Fig. 5b). This contributes to the "smoothing" of the $\mathrm{CO}_{2}$ capture ratio trend (Fig. 5a). Similarly, the volume of solvent holdup in the plant (buffer/storage tanks, column sumps) also has a role in buffering variations in the system. Therefore, having large liquid vessels that limit the transient behaviour during slow disturbances are advantageous during fast disturbances as they buffer the dynamics and prevent departure from steady state set-points of the $\mathrm{CO}_{2}$ capture process. However, this only occurs if the initial and final state of the disturbed variable are similar, otherwise the time required to reach a new steady-state is dictated by the large liquid hold-ups and the transport delays in the capture plant.

\subsection{Effect of Steam Extraction During Dy- namic Operation of the NGCC}

In this case, the disturbance in the steam extraction valve was imposed simultaneously 


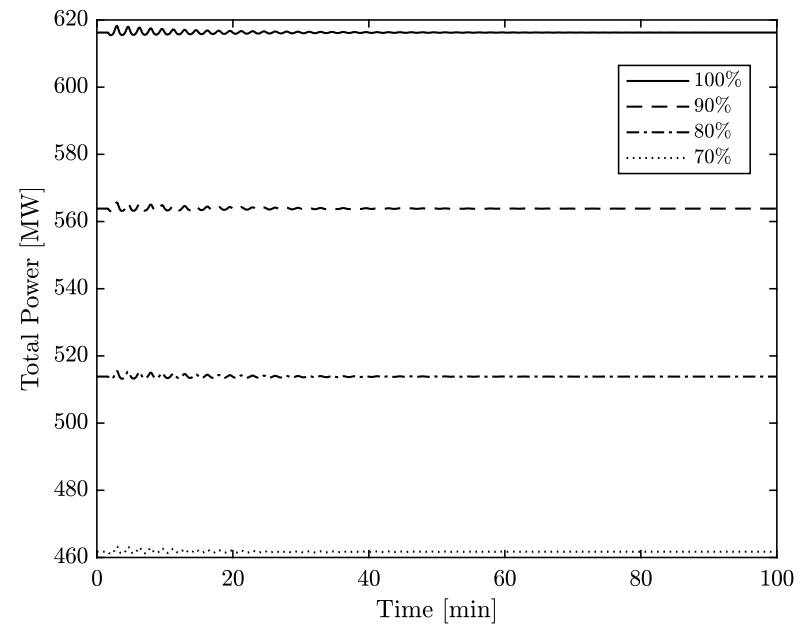

(a) Total power generation of the natural gas combined cycle.

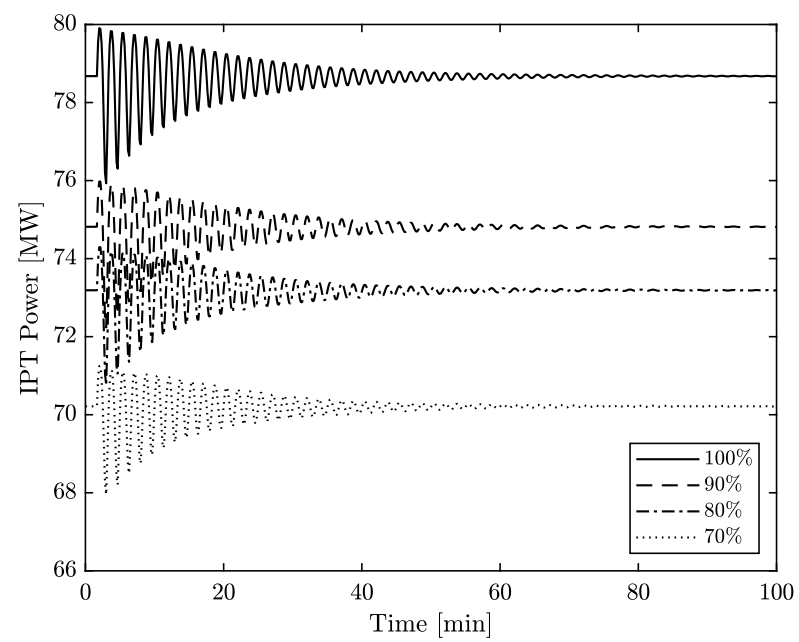

(c) Power generation of the intermediate-pressure steam turbine.

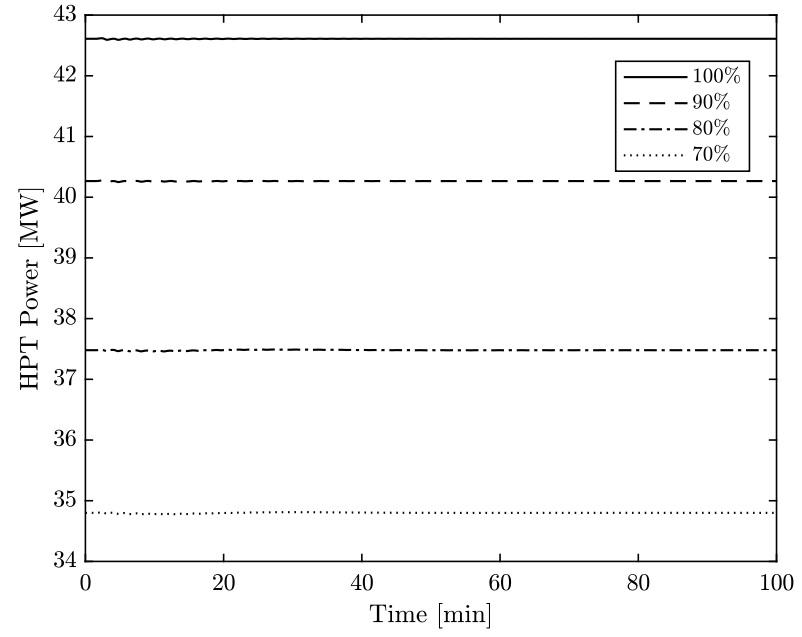

(b) Power generation of the high-pressure steam turbine.

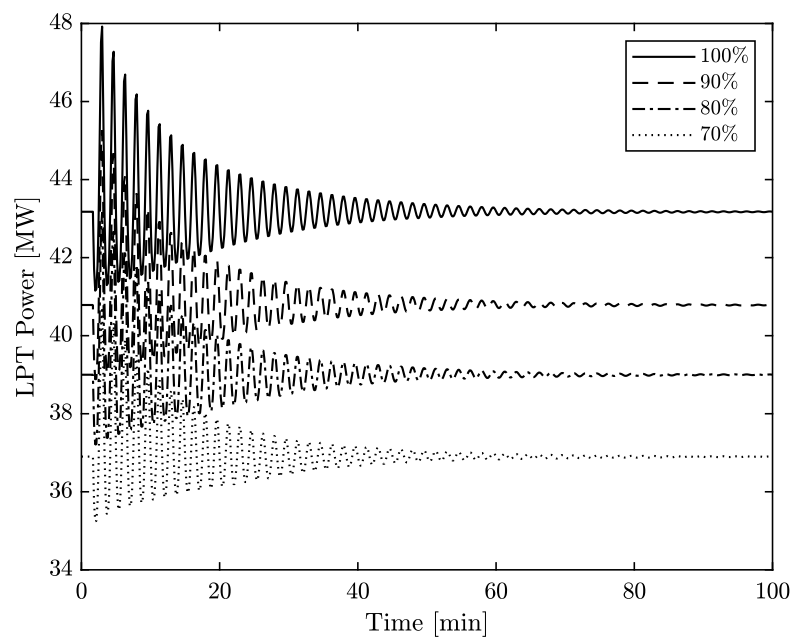

(d) Power generation of the low-pressure steam turbine.

Figure 4: Variation in power generation in the natural gas combined cycle and the steam turbine sections (HP, IP and LP) due to the fluctuation in the steam extracted from the IP-LP crossover at different gas turbine loads.

with a change of load in the gas turbine. The 712 same parameters, i.e. power generation distri- 713 bution and key performance indicators, were 714 analysed in the NGCC and $\mathrm{CO}_{2}$ capture plant, 715 respectively.

\subsubsection{Power Generation Performance} valve was implemented during a gas 720 turbine load change from $100 \%$ to $70 \%$. This 721 demonstrates the effect of fast variations in the 722 steam extraction during transient operation of 723 the NGCC. Fig. 6 represents the power gen- 724 eration profile of the overall power plant and 725 of each section of the steam turbine. Fig. 7726 shows key process variables of the $\mathrm{CO}_{2}$ cap- 727 ture plant during the transient operation of the power plant with varying steam extraction. Figs. 6 and 7 show performance with fast dynamic fluctuations in the steam extraction valve (black line), and without fluctuations (red line).

During transient operation, the change in gas turbine load dictates power generation (Fig. 6a). This is because the oscillations generated by the steam extraction valve have a negligible effect on power generation in NGCC plants. This occurs regardless of the fluctuations in the IP and LP steam turbines, represented in Figs. 6c and 6d respectively, due to the low contribution of these units to the total power production (see Fig. 3). As steam 


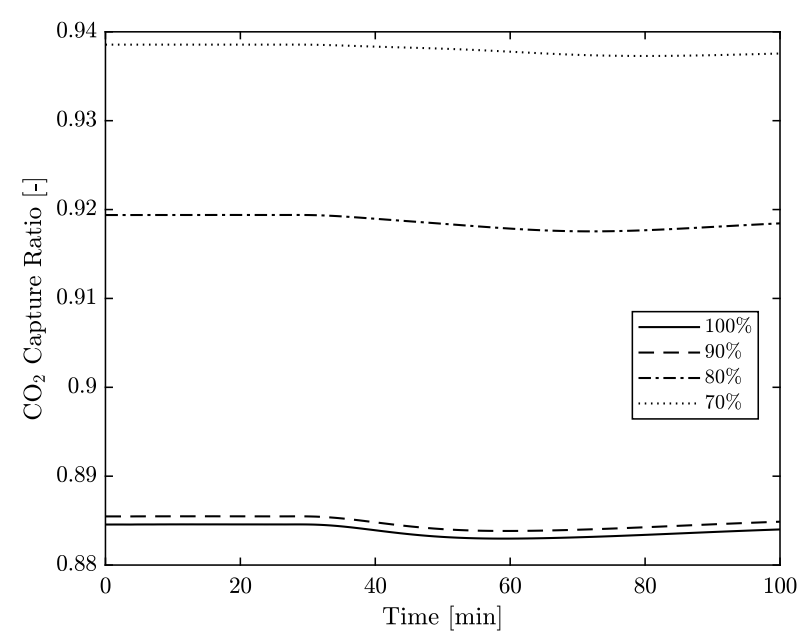

(a) $\mathrm{CO}_{2}$ capture ratio.

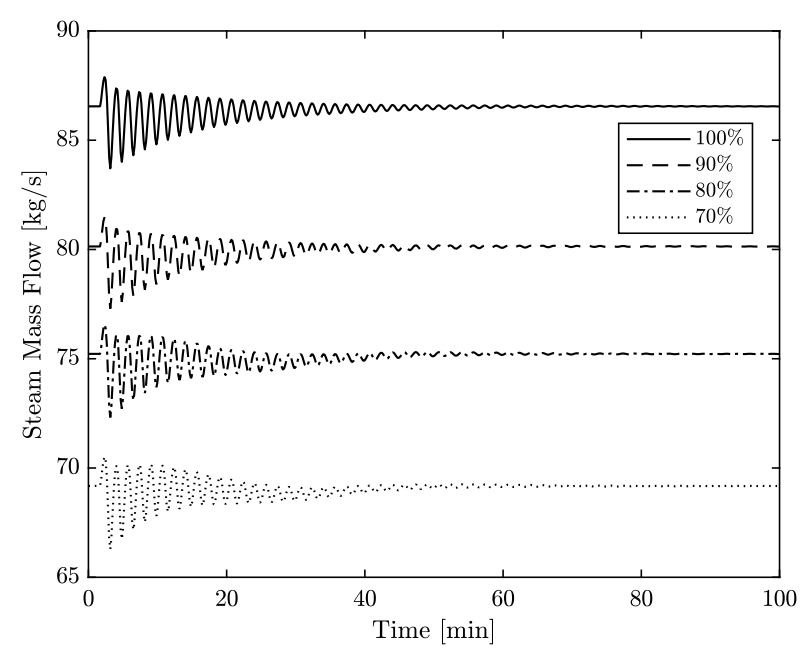

(c) Steam mass flow rate.

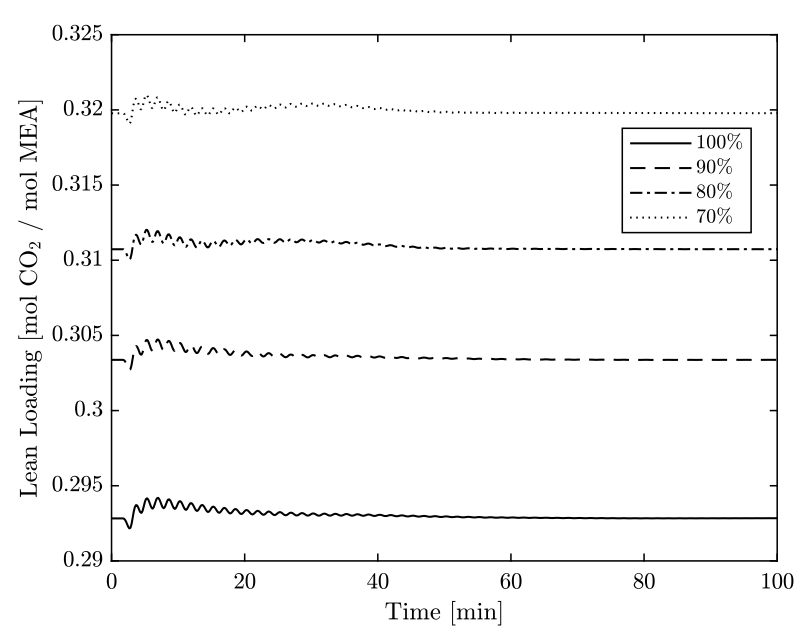

(b) Lean solvent $\mathrm{CO}_{2}$ concentration.

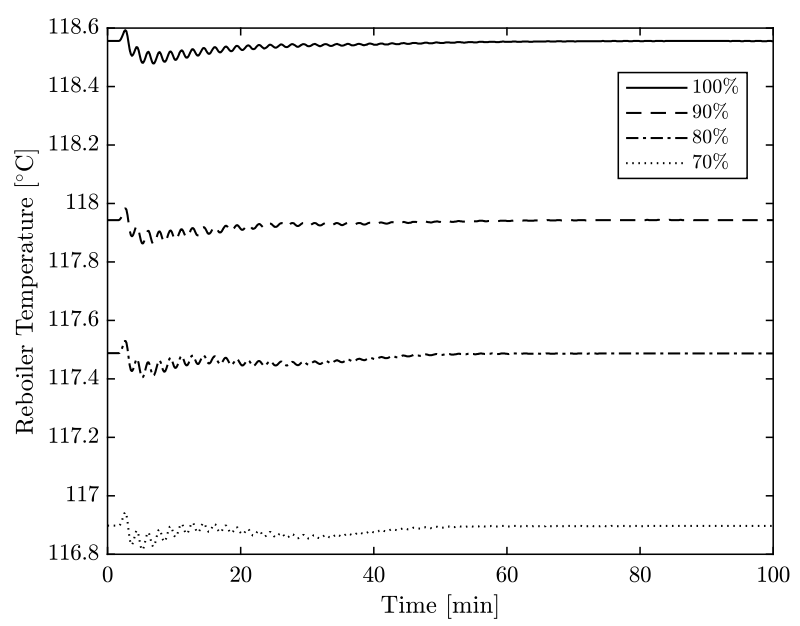

(d) Reboiler temperature.

Figure 5: Dynamic behaviour of key process variables in the post-combustion capture plant during steady-state operation of the natural gas combined cycle. Transient operation is driven by opening variations of the steam extraction valve.

extraction does not have a notable effect on 744 the total power generation, the NGCC power 745 plant may operate independently of the cap- 746 ture plant without any penalty on its dynamic 747 performance.

\subsection{2. $\mathrm{CO}_{2}$ Capture Performance}

The transient behaviour of the $\mathrm{CO}_{2}$ capture 751 process is governed by the variation in flue gas 752 conditions due to changes in gas turbine load 753 and the steam flow rate fed to the reboiler, 754 which depends on the steam availability in the 755 power plant and the opening of the steam ex- 756 traction valve. The gas turbine load deter- 757 mines steam availability for extraction at the 758 IP-LP crossover valve, and hence dictates the 759 dynamic performance of the reboiler and strip- 760 per. The scenario without fast dynamic fluctuations in steam extraction is represented by the red line in Fig. 7, whereas the behaviour with fast valve fluctuations is shown by the black line.

For a given steam extraction valve opening, the decrease in steam availability that arises from the change in gas turbine load results in less steam extraction (Fig. 7c), which leads to more pronounced variations in the reboiler temperature and lean loading. Unlike the fast disturbances of imposed fluctuations in the opening of the steam extraction valve, the gas turbine load change disturbance is slower. There is sufficient time for heat transfer from the steam to the reboiler fluid, thus reboiler temperature follows the same trajectory as the 


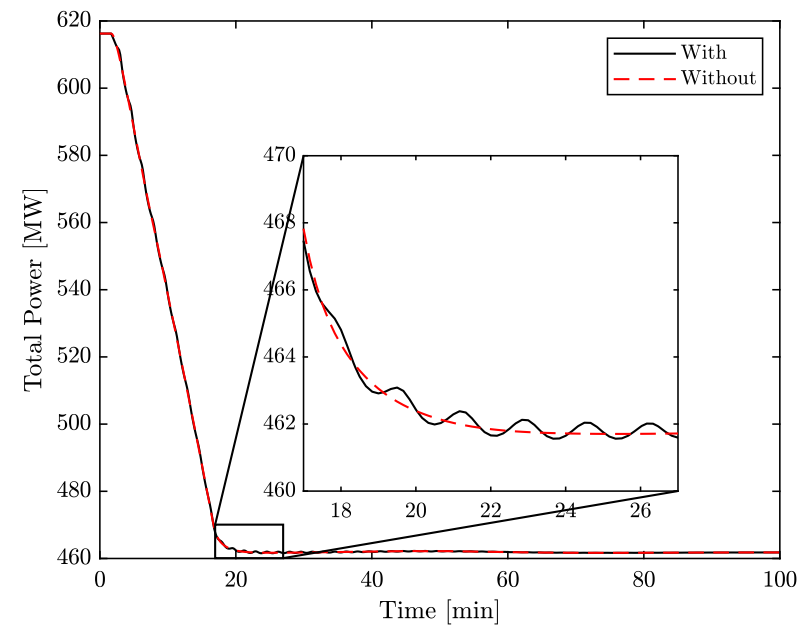

(a) Total power generation of the natural gas combined cycle.

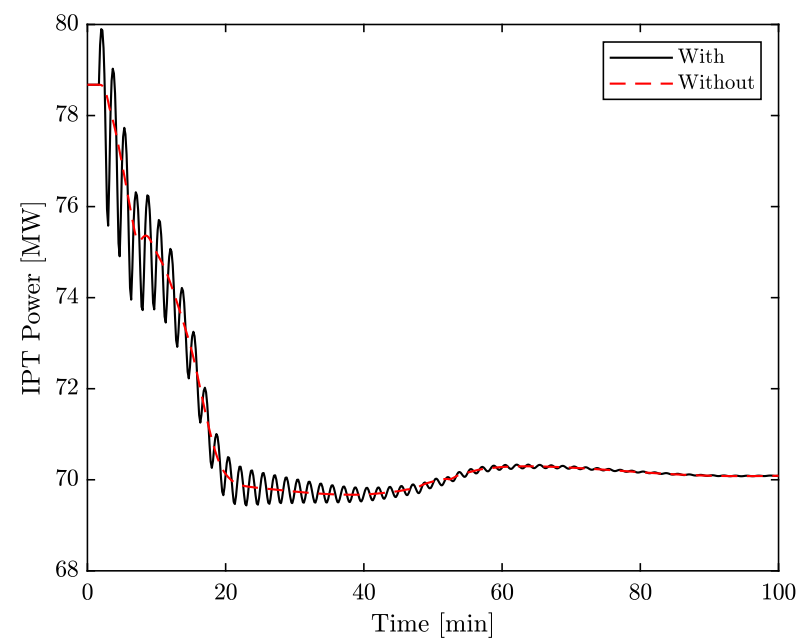

(c) Power generation of the intermediate-pressure steam turbine.

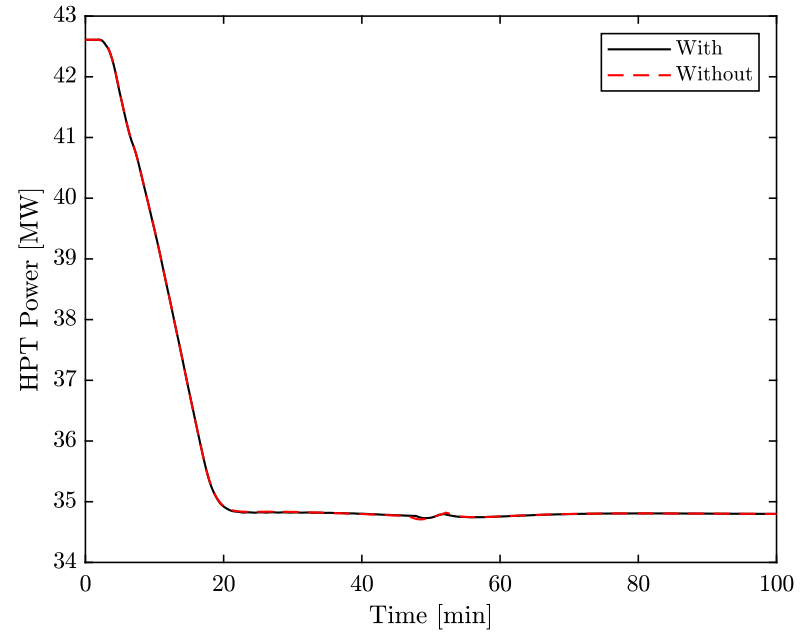

(b) Power generation of the high-pressure steam turbine.

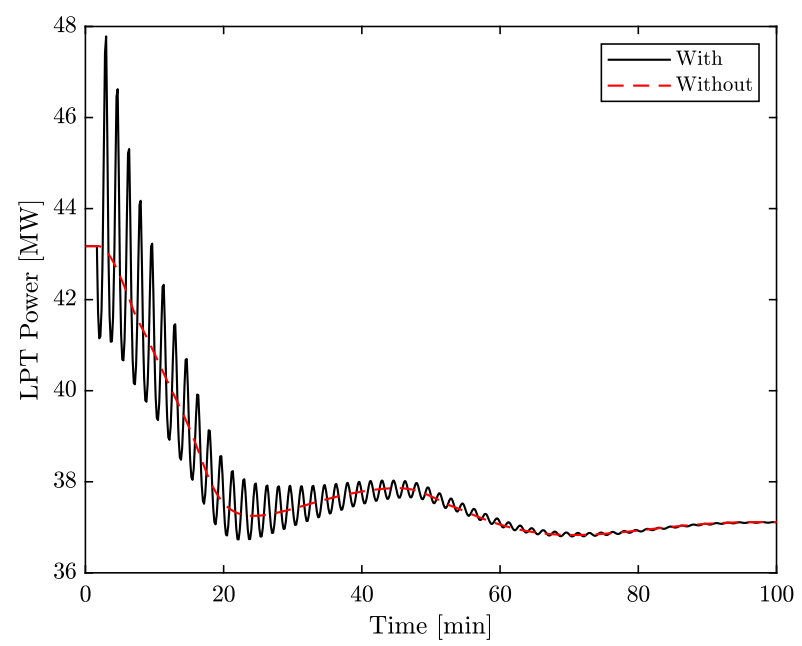

(d) Power generation of the low-pressure steam turbine.

Figure 6: Power generation dynamic behaviour during a gas turbine load change from $100 \%$ to $70 \%$ with and without fast dynamic fluctuations in the steam extraction valve.

steam flow rate. Similarly, as the reboiler tem- 777 perature dictates the degree of solvent regen- 778 eration, lean loading has the same trend. The 779 variation in reboiler temperature and lean load- 780 ing have an apparent effect on the $\mathrm{CO}_{2}$ capture 781 ratio.

In contrast, fast dynamic fluctuations in the 783 steam extraction do not disrupt the transient 784 behaviour of the plant as the main process vari- 785 ables follow the same trajectory as in the sce- 786 nario without fluctuations (red and black lines in Fig. 7). Thus, steam availability in the steam cycle has a more pronounced affect on the dynamic response of the $\mathrm{CO}_{2}$ capture plant 788 than the opening of the steam extraction valve. 789 Similar to the steady-state operation results, 790 a smoothing effect of the fast fluctuations in steam extraction was observed during dynamic operation. Due to the fluctuations in the steam valve being so rapid, which subsequently results in equally rapid steam flow rate fluctuations, there is insufficient time for heat to transfer from the steam to the reboiler fluid. Thus, the reboiler temperature, lean loading and $\mathrm{CO}_{2}$ capture rate are practically the same with and without steam valve fluctuations.

\section{Conclusions}

There are essentially two ways to integrate post-combustion $\mathrm{CO}_{2}$ capture with thermal power plants. The first simply connects the 


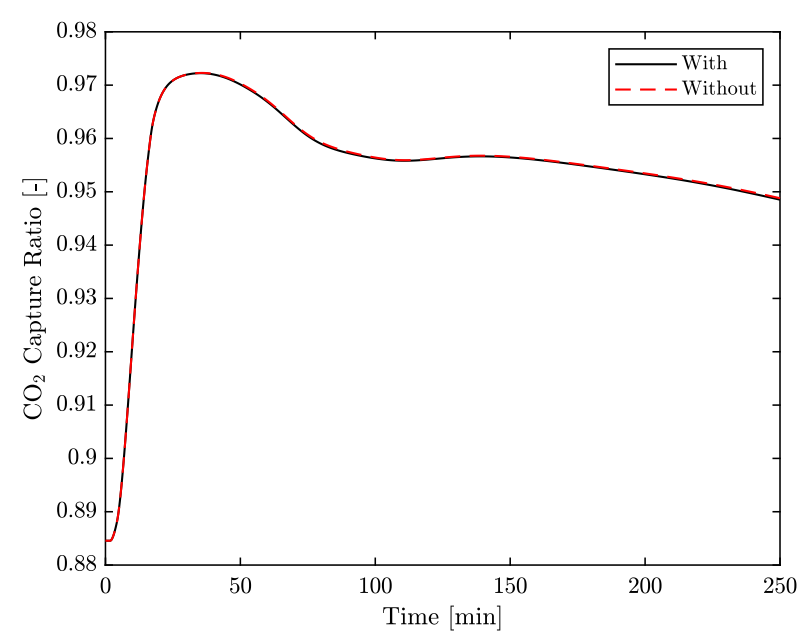

(a) $\mathrm{CO}_{2}$ capture ratio.

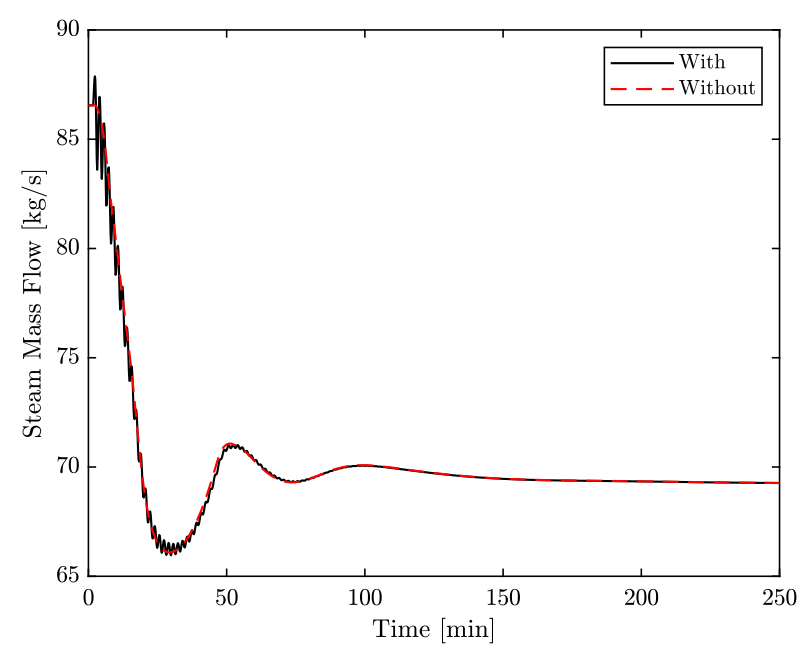

(c) Steam mass flow rate.

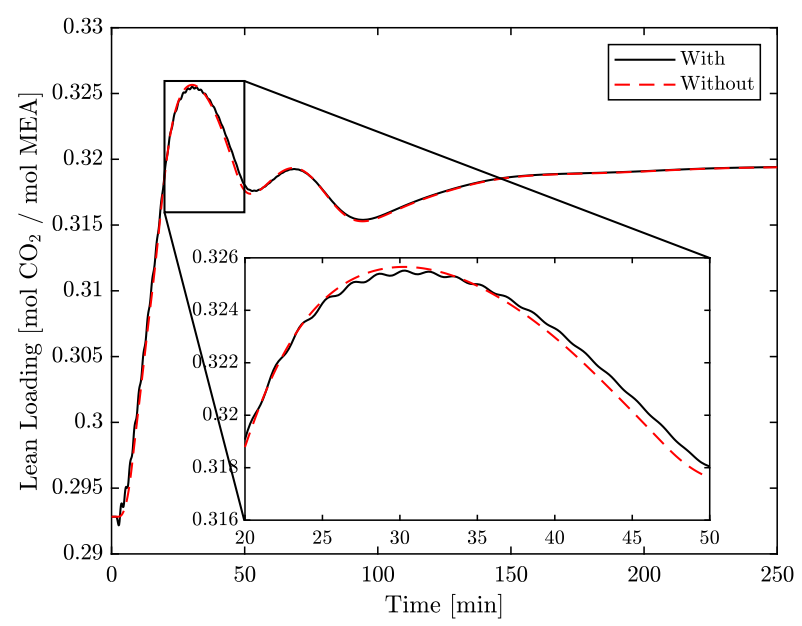

(b) Lean solvent $\mathrm{CO}_{2}$ concentration.

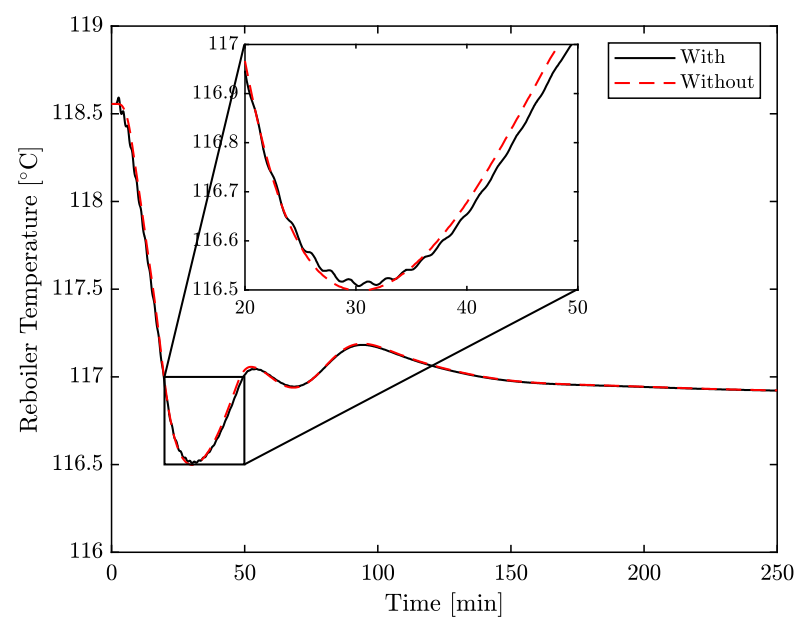

(d) Reboiler temperature.

Figure 7: Dynamic behaviour of key process variables in the post-combustion capture plant during a gas turbine load change from $100 \%$ to $70 \%$ with and without fast dynamic fluctuations in the steam extraction valve.

exhaust gas with the capture process, and the 809 energy required for solvent regeneration is sup- 810 plied externally. Whilst this does present the 811 challenge of mitigating any emissions associ- 812 ated with providing that energy, it does en- 813 tirely avoid imposing constraints on the oper- 814 ability of the power plant - this form of CCS is 815 an entirely "end of pipe" solution. The second, 816 more commonly discussed, option involves the ${ }_{817}$ extraction of steam from between the interme- ${ }_{818}$ diate and low pressure steam turbines. This ${ }_{819}$ avoids the challenge of having to mitigate ad- 820 ditional emissions, but has led to concerns as ${ }_{821}$ to the effect this strategy might have on the ${ }_{822}$ operability of the power plant, since these two ${ }_{823}$ plants operate in two different transient time- 824 scales. This work seeks to address this chal- 825 lenge by analysing the effect of disturbances ${ }_{826}$ on power generation capacity, specifically disturbances with faster dynamics than the dominant dynamics of the power plant.

Transient power generation was assessed during steady-state and dynamic operation of the power plant by modifying the valve opening for steam extraction in the short time-scales defined by the power plant. Since the gas turbine generates most of the total power, fluctuations in the steam extraction valve have no impact on the power generation capacity. In steadystate power plant operation, the total power generation remains unaltered with small fluctuations around the steady-state value that are easily compensated for with small adjustments in the gas turbine. During transient operation of the power plant, the change of load in the gas turbine drives the dynamic behaviour of the 
NGCC. Hence, disturbances in steam extrac- 878 tion can be regarded as noise around the tran- 879 sient value dictated by the gas turbine load. $\quad 880$

Different behaviour may be expected from ${ }^{881}$ power plants where the steam cycle gener- ${ }^{882}$ ates most of the power, e.g. coal-fired power ${ }^{883}$ plants. Valve opening fluctuations in this type ${ }^{884}$ of power plants might lead to larger variations ${ }^{885}$ in the total power generation since larger steam ${ }^{886}$ mass flow rates are required in the steam tur- ${ }^{887}$ bine. Therefore, steam extraction from power 888 plants dominated by the steam cycle perfor- ${ }^{889}$ mance has greater influence on power genera- 890 tion, and may add value to the flexible perfor- 891 mance of NGCCs. However, this behaviour is ${ }^{892}$ yet to be demonstrated by dynamic studies. $\quad 893$

The transient behaviour of the capture plant ${ }^{894}$ was similar to the power plant since its dynam- ${ }^{895}$ ics is dominated by the operating conditions in ${ }^{896}$ the gas turbine and steam cycle. A change in ${ }^{897}$ gas turbine load results in different flue gas flow ${ }^{89}$ rate and steam availability, thereby influenc- ${ }^{899}$ ing the performance of the capture plant. The ${ }^{900}$ varying steam extraction only leads to small ${ }^{901}$ fluctuations, with the trends following the same ${ }^{902}$ trajectory as the profile of the scenario varying ${ }^{903}$ valve opening variations. These small fluctu- 904 ations disturb the process and are smoothed 905 along the capture plant. This effect is demon- 906 strated by the disturbance starting as signif 907 cant fluctuations in steam flow rate, which 908 dampen to become smaller fluctuations in re- ${ }^{909}$ boiler temperature and lean loading, then fi- ${ }^{910}$ nally resulting in a smooth $\mathrm{CO}_{2}$ capture ra- ${ }^{911}$ tio profile. The dampening effect is attributed ${ }^{912}$ to the heat capacitance of the system and the ${ }^{913}$ buffering of the disturbance in the large liquid hold-ups. Thus, the large vessels of the capture plant are advantageous for small, fast ${ }^{915}$ variations as they buffer disturbances, avoiding ${ }_{916}$ departure from steady-state conditions. This ${ }_{917}$ phenomena occurs at both steady and dynamic ${ }_{918}$ operation of the NGCC.

These results highlight the benefits and dis- 920 advantages of having large liquid hold-ups in 921 the capture plant. Large storage vessels allow 922 the buffering of the fast variations in the pro- 923 cess variables. However, these vessels also lead 924 to slow transients, increasing the time to reach 925 a new steady state to several hours, which will 926 potentially limit the flexibility of the capture 927 plant. This suggests that the post-combustion capture plants can be operated optimally and independently of the power plant. Imposing tight controls on specific variables to minimize the difference between a value and its set-point a could limit the flexibility of the integrated system. Instead, the capture plant should aim at finding a new optimal operation point given the boundary conditions imposed by the power plant. This is because any changes in steam extraction to achieve optimal operating conditions would not affect power plant performance, as shown in this work. Therefore, the decarbonisation of an NGCC via postcombustion $\mathrm{CO}_{2}$ capture does not appear to impose any limitation on the flexibility or operability of the underlying power plant in terms of power generation.

Therefore, one key research challenge is to develop control strategies and operation protocols that enable optimal operation of the capture plant that is essentially independent from the operation of the power plant rather than load following mode with fixed capture ratios (Sahraei and Ricardez-Sandoval, 2014; Bankole et al., 2018; Decardi-Nelson et al., 2018). This may lead to improvements in the financial viability of the CCS project as steam extraction fluctuations have no impact on power generation. The development of process control structures designed for flexible operation and dynamic conditions will be an important area of future research (Åkesson et al., 2012; Hauger et al., 2019). Finally, the development of reliable start-up and shut-down protocols for CCSequipped power plants so as to avoid increasing the carbon intensity of these assets is a priority.

\section{Acknowledgements}

This work has been financially supported by the Department of Energy and Process Engineering at the Norwegian University of Science and Technology - NTNU, and the funding from the Research Councils UK (RCUK) under grants EP/M001369/1 (MESMERISECCS), EP/M015351/1 (Opening New Fuels for UK Generation), EP/N024567/1 (CCSInSupply), and NE/P019900/1 (GGR Opt). The authors also thank Dr. Rubén Mocholí Montañés for providing the dynamic model of the power plant and for his valuable advice. 


\section{References}

Adams, T., Mac Dowell, N., 2016. Off-design point ${ }^{992}$ modelling of a 420 MW CCGT power plant integrated with an amine-based post-combustion $\mathrm{CO}_{2}{ }_{995}^{994}$ capture and compression process. Applied energy 178, 681-702.

Åkesson, J., Laird, C. D., Lavedan, G., Prölß, K., ${ }^{997}$ Tummescheit, H., Velut, S., Zhu, Y., 2012. Nonlinear model predictive control of a $\mathrm{CO}_{2}$ post-combustion ${ }_{1000}$ absorption unit. Chemical Engineering \& Technology ${ }_{1001}^{1000}$ 35 (3), 445-454.

Alobaid, F., Mertens, N., Starkloff, R., Lanz, T., ${ }_{1003}^{1002}$ Heinze, C., Epple, B., 2017. Progress in dynamic sim- ${ }_{1004}$ ulation of thermal power plants. Progress in Energy ${ }_{1005}$ and Combustion Science 59, 79-162.

Bankole, T., Jones, D., Bhattacharyya, D., Turton, R. ${ }^{1006}$ Zitney, S. E., 2018. Optimal scheduling and its Lya- ${ }_{1008}$ punov stability for advanced load-following energy ${ }_{1009}$ plants with $\mathrm{CO}_{2}$ capture. Computers \& Chemical ${ }_{1010}^{1009}$ Engineering 109, 30-47.

1011

Botero, C., Finkenrath, M., Bartlett, M., Chu, R., Choi, ${ }_{1012}$ G., Chinn, D., 2009. Redesign, optimization, and ${ }_{1013}^{1012}$ economic evaluation of a natural gas combined cy- ${ }_{1014}$ cle with the best integrated technology $\mathrm{CO}_{2}$ capture. ${ }_{1015}$ Energy Procedia 1 (1), 3835-3842.

Bui, M., Adjiman, C. S., Bardow, A., Anthony, E. J., ${ }_{1017}^{1016}$ Boston, A., Brown, S., Fennell, P. S., Fuss, S., 1018 Galindo, A., Hackett, L. A., et al., 2018a. Carbon ${ }_{1019}$ capture and storage (CCS): the way forward. Energy ${ }_{1020}$ \& Environmental Science 11 (5), 1062-1176.

Bui, M., Flø, N. E., de Cazenove, T., Mac Dowell, N., ${ }^{1021}$ 2020. Demonstrating flexible operation of the Tech- ${ }^{1022}$ nology Centre Mongstad (TCM) $\mathrm{CO}_{2}$ capture plant. ${ }_{1024}$ International Journal of Greenhouse Gas Control 93, ${ }_{1025}^{1024}$ 102879 .

Bui, M., Gunawan, I., Verheyen, V., Feron, P., Meule- ${ }_{1027} 1026$ man, E., 2016. Flexible operation of CSIRO's post- ${ }_{1028}$ combustion $\mathrm{CO}_{2}$ capture pilot plant at the AGL Loy ${ }_{1029}$ Yang power station. International Journal of Green- ${ }_{1030}$ house Gas Control 48, 188-203.

Bui, M., Gunawan, I., Verheyen, V., Feron, P., Meule- ${ }^{1031}$ man, E., Adeloju, S., 2014. Dynamic modelling and ${ }_{1033}^{1032}$ optimisation of flexible operation in post-combustion ${ }_{1034}$ $\mathrm{CO}_{2}$ capture plants A review. Computers \& Chem- ${ }_{1035}{ }_{1034}$ ical Engineering 61, 245-265.

Bui, M., Tait, P., Lucquiaud, M., Mac Dowell, N., ${ }^{1036}$ 2018b. Dynamic operation and modelling of amine- ${ }^{1037}$ based $\mathrm{CO}_{2}$ capture at pilot scale. International Jour- ${ }_{1039}$ nal of Greenhouse Gas Control 79, 134-153.

Dassault Systemes, 2016. https://www.3ds.com/ ${ }_{1041}^{1040}$ products-services/catia/products/dymola/. 1042 Decardi-Nelson, B., Liu, S., Liu, J., 2018. Im- ${ }_{1043}^{1042}$ proving Flexibility and Energy Efficiency of Post- ${ }_{1044}$ Combustion $\mathrm{CO}_{2}$ Capture Plants Using Economic ${ }_{1045}$ Model Predictive Control. Processes 6 (9), 135.

Dutta, R., Nord, L. O., Bolland, O., 2017. Selection ${ }_{1047}^{1046}$ and design of post-combustion $\mathrm{CO}_{2}$ capture process ${ }_{1048}$ for $600 \mathrm{MW}$ natural gas fueled thermal power plant ${ }_{1049}$ based on operability. Energy 121, 643-656.

Eser, P., Chokani, N., Abhari, R., 2017. Operational ${ }_{1051}^{1050}$ and financial performance of fossil fuel power plants ${ }_{1052}^{1051}$ within a high renewable energy mix. Journal of the ${ }_{1053}^{1052}$ Global Power and Propulsion Society 1, 16-27.
Fernandez, E. S., del Rio, M. S., Chalmers, H., Khakharia, P., Goetheer, E. L., Gibbins, J., Lucquiaud, M., 2016. Operational flexibility options in power plants with integrated post-combustion capture. International Journal of Greenhouse Gas Control 48, 275-289.

Flø, N. E., Kvamsdal, H. M., Hillestad, M., Mejdell, T., 2016. Dominating dynamics of the post-combustion $\mathrm{CO}_{2}$ absorption process. Computers \& Chemical Engineering $86,171-183$.

Garðarsdóttir, S. O., Montanes, R. M., Normann, F., Nord, L. O., Johnsson, F., 2017. Effects of $\mathrm{CO}_{2}-$ absorption control strategies on the dynamic performance of a supercritical pulverized-coal-fired power plant. Industrial \& Engineering Chemistry Research 56 (15), 4415-4430.

Garðarsdóttir, S. Ó., Normann, F., Andersson, K., Prölß, K., Emilsdóttir, S., Johnsson, F., 2015. Postcombustion $\mathrm{CO}_{2}$ capture applied to a state-of-the-art coal-fired power plant: The influence of dynamic process conditions. International Journal of Greenhouse Gas Control 33, 51-62.

González-Salazar, M. A., Kirsten, T., Prchlik, L., 2017. Review of the operational flexibility and emissions of gas-and coal-fired power plants in a future with growing renewables. Renewable and Sustainable Energy Reviews 82, 1497-1513.

Hauger, S. O., Flø, N. E., Kvamsdal, H., Gjertsen, F., Mejdell, T., Hillestad, M., 2019. Demonstration of non-linear model predictive control of postcombustion $\mathrm{CO}_{2}$ capture processes. Computers \& Chemical Engineering 123, 184-195.

He, Z., Ricardez-Sandoval, L. A., 2016. Dynamic modelling of a commercial-scale $\mathrm{CO}_{2}$ capture plant integrated with a natural gas combined cycle (NGCC) power plant. International Journal of Greenhouse Gas Control 55, 23-35.

Hentschel, J., Spliethoff, H., et al., 2016. A parametric approach for the valuation of power plant flexibility options. Energy Reports 2, 40-47.

Heuberger, C. F., Rubin, E. S., Staffell, I., Shah, N., Mac Dowell, N., 2017a. Power capacity expansion planning considering endogenous technology cost learning. Applied Energy 204, 831-845.

Heuberger, C. F., Staffell, I., Shah, N., Mac Dowell, N., 2016. Quantifying the value of CCS for the future electricity system. Energy \& Environmental Science 9 (8), 2497-2510.

Heuberger, C. F., Staffell, I., Shah, N., Mac Dowell, N., 2017b. A systems approach to quantifying the value of power generation and energy storage technologies in future electricity networks. Computers \& Chemical Engineering 107, 247-256.

IEA, 2018a. $\mathrm{CO}_{2}$ Emissions from Fuel Combustion 2018. https://www.iea.org/statistics/ co2emissions/.

IEA, 2018b. World Energy Outlook 2018: Executive Summary. https://webstore.iea.org/download/ summary/190? fileName=English-WEO-2018-ES . pdf.

IPCC, 2005. IPCC Special Report on Carbon Dioxide Capture and Storage. Prepared by Working Group III of the Intergovernmental Panel on Climate 
Change [Metz, B., O. Davidson, H. C. de Coninck, 1117 M. Loos, and L. A. Meyer (eds.)]. Cambridge Uni- 1118 versity Press, Cambridge, United Kingdom and New 1119 York, NY, USA.

IPCC, 2014. Climate Change 2014: Synthesis Report. 1121 Contribution of Working Groups I, II and III to the 1122 Fifth Assessment Report of the Intergovernmental 1123 Panel on Climate Change [Core Writing Team, R.K. 1124 Pachauri and L.A. Meyer (eds.)], IPCC, Geneva, 1125 Switzerland.

IPCC, 2018. Summary for Policymakers. In: Global 1127 warming of $1.5^{\circ} \mathrm{C}$. An IPCC Special Report on 1128 the impacts of global warming of $1.5^{\circ} \mathrm{C}$ above pre- 1129 industrial levels and related global greenhouse gas 1130 emission pathways, in the context of strengthening 1131 the global response to the threat of climate change, 1132 sustainable development, and efforts to eradicate 1133 poverty. [V. Masson-Delmotte, P. Zhai, H. O. Prt-1134 ner, D. Roberts, J. Skea, P. R. Shukla, A. Pirani, W. 1135 Moufouma-Okia, C. Pan, R. Pidcock, S. Connors, J. 1136 B. R. Matthews, Y. Chen, X. Zhou, M. I. Gomis, 1137 E. Lonnoy, T. Maycock, M. Tignor, T. Waterfield 1138 (eds.)]. World Meteorological Organization, Geneva, 1139 Switzerland.

1140

Jonshagen, K., Sammak, M., Genrup, M., 2012. Post- 1141 combustion $\mathrm{CO}_{2}$ capture for combined cycles uti-1142 lizing hot-water absorbent regeneration. Journal of 1143 Engineering for Gas Turbines and Power 134 (1), 1144 011702.

Jordal, K., Ystad, P. A. M., Anantharaman, R.,1146 Chikukwa, A., Bolland, O., 2012. Design-point and 1147 part-load considerations for natural gas combined cy-1148 cle plants with post combustion capture. Interna-1149 tional Journal of Greenhouse Gas Control 11, 271-1150 282 .

Kehlhofer, R., Hannemann, F., Rukes, B., Stirnimann, 1152 F., 2009. Combined-Cycle Gas \& Steam Turbine 1153 Power Plants. Pennwell Books.

1154

Kondziella, H., Bruckner, T., 2016. Flexibility require- 1155 ments of renewable energy based electricity systems-1156 A review of research results and methodologies. Re- 1157 newable and Sustainable Energy Reviews 53, 10-22. 1158

Kvamsdal, H. M., Rochelle, G. T., 2008. Effects of the 1159 temperature bulge in $\mathrm{CO}_{2}$ absorption from flue gas 1160 by aqueous monoethanolamine. Industrial \& Engi-1161 neering Chemistry Research 47 (3), 867-875. 1162

Lawal, A., Wang, M., Stephenson, P., Koumpouras, G., 1163 Yeung, H., 2010. Dynamic modelling and analysis 1164 of post-combustion $\mathrm{CO}_{2}$ chemical absorption process 1165 for coal-fired power plants. Fuel 89 (10), 2791-2801. 1166

Lawal, A., Wang, M., Stephenson, P., Obi, O., 2012.1167 Demonstrating full-scale post-combustion $\mathrm{CO}_{2}$ cap- 1168 ture for coal-fired power plants through dynamic 1169 modelling and simulation. Fuel 101, 115-128.

1170

Ljung, L., 1987. System identification: theory for the 1171 user. Prentice-hall.

1172

Lucquiaud, M., Chalmers, H., Gibbins, J., 2009.1173 Capture-ready supercritical coal-fired power plants 1174 and flexible post-combustion $\mathrm{CO}_{2}$ capture. Energy 1175 Procedia 1 (1), 1411-1418.

1176

Mac Dowell, N., Shah, N., 2013. Identification of the 1177 cost-optimal degree of $\mathrm{CO}_{2}$ capture: An optimisation 1178 study using dynamic process models. International 1179
Journal of Greenhouse Gas Control 13, 44-58.

Mac Dowell, N., Shah, N., 2014. Dynamic modelling and analysis of a coal-fired power plant integrated with a novel split-flow configuration post-combustion $\mathrm{CO}_{2}$ capture process. International Journal of Greenhouse Gas Control 27, 103-119.

Mac Dowell, N., Shah, N., 2015. The multi-period optimisation of an amine-based $\mathrm{CO}_{2}$ capture process integrated with a super-critical coal-fired power station for flexible operation. Computers \& Chemical Engineering 74, 169-183.

Mac Dowell, N., Staffell, I., 2016. The role of flexible CCS in the UK's future energy system. International Journal of Greenhouse Gas Control 48, 327-344.

Mechleri, E., Fennell, P. S., Mac Dowell, N., 2017a. Optimisation and evaluation of flexible operation strategies for coal-and gas-ccs power stations with a multi-period design approach. International Journal of Greenhouse Gas Control 59, 24-39.

Mechleri, E., Lawal, A., Ramos, A., Davison, J., Mac Dowell, N., 2017b. Process control strategies for flexible operation of post-combustion $\mathrm{CO}_{2}$ capture plants. International Journal of Greenhouse Gas Control 57, 14-25.

Modelica Association, 2019. https://www.modelica. org/.

Modelon, 2015. Thermal Power Library. https://www . modelon.com/library/thermal-power-library/.

Montañés, R., Flø, N., Nord, L., 2017a. Dynamic process model validation and control of the amine plant at $\mathrm{CO}_{2}$ Technology Centre Mongstad. Energies 10 (10), 1527.

Montañés, R. M., Flø, N. E., Nord, L. O., 2018. Experimental results of transient testing at the amine plant at Technology Centre Mongstad: Open-loop responses and performance of decentralized control structures for load changes. International Journal of Greenhouse Gas Control 73, 42-59.

Montañés, R. M., Garðarsdóttir, S. Ó., Normann, F., Johnsson, F., Nord, L. O., 2017b. Demonstrating load-change transient performance of a commercialscale natural gas combined cycle power plant with post-combustion $\mathrm{CO}_{2}$ capture. International Journal of Greenhouse Gas Control 63, 158-174.

Montañés, R. M., Korpås, M., Nord, L. O., Jaehnert, S., 2016. Identifying operational requirements for flexible CCS power plant in future energy systems. Energy Procedia 86, 22-31.

Rezazadeh, F., Gale, W. F., Hughes, K. J., Pourkashanian, M., 2015. Performance viability of a natural gas fired combined cycle power plant integrated with post-combustion $\mathrm{CO}_{2}$ capture at part-load and temporary non-capture operations. International Journal of Greenhouse Gas Control 39, 397-406.

Rúa, J., Agromayor, R., Hillestad, M., Nord, L. O., 2020. Optimal dynamic operation of natural gas combined cycles accounting for stresses in thickwalled components. Applied Thermal Engineering Accepted.

Sahraei, M. H., Ricardez-Sandoval, L. A., 2014. Controllability and optimal scheduling of a $\mathrm{CO}_{2}$ capture plant using model predictive control. International Journal of Greenhouse Gas Control 30, 58-71. 
1180

1181

1182

1183

1184

1185

1186

1187

1188

1189

Tait, P., Buschle, B., Ausner, I., Valluri, P., Wehrli, M., Lucquiaud, M., 2016. A pilot-scale study of dynamic response scenarios for the flexible operation of post-combustion $\mathrm{CO}_{2}$ capture. International Journal of Greenhouse Gas Control 48, 216-233.

Thermoflow, 2014. GT Pro 24.0. Thermoflow Inc.

Wellner, K., Marx-Schubach, T., Schmitz, G., 2016. Dynamic behavior of coal-fired power plants with postcombustion $\mathrm{CO}_{2}$ capture. Industrial \& Engineering Chemistry Research 55 (46), 12038-12045. 